\title{
Precariedad y viabilidad de la pequeña producción campesina en el nuevo milenio
}

Precariousness and viability of small peasant production in the new millennium

Precariedade e viabilidade da pequena produção camponesa no novo milênio

\section{Humberto de Luna López ${ }^{1}$}

\begin{abstract}
Recibido: 14 de marzo de 2020
Aprobado: 18 de diciembre de 2020

Publicado: 12 de abril de 2021

Cómo citar este artículo:

Luna, H. (2021). Precariedad y viabilidad de la pequeña producción campesina en el nuevo milenio. Cooperativismo \& Desarrollo, 29(119), 1-30. doi: https://doi.org/10.16925/2382-4220.2021.01.08
\end{abstract}

Artículo de investigación. https://doi.org/10.16925/2382-4220.2021.01.08

1 Doctor en Ciencias Sociales y Humanidades de la Universidad Autónoma de Zacatecas. Profesor investigador de la Unidad Académica de Economía de la Universidad Autónoma de Zacatecas, México.

Correo electrónico: humberto_deluna@yahoo.com.mx ORCID: https://orcid.org/0000-0002-8219-9740 


\section{Resumen}

El objetivo de este artículo es exponer los procesos de reconfiguración de la sociedad campesina, para enfrentar la precariedad y perpetuarse como segmento de población que presiona los salarios con tendencia a la baja, al sumar al crecimiento de los excedentes de población, en una provincia del centro-norte de México llamada Zacatecas. En este lugar, 4 de cada 10 zacatecanos viven en la zona rural; además, en 2007 existían 124.861 pequeños productores y para el 2016 sumaban 255.236, principalmente ejidatarios y comuneros que producen para el autoconsumo en tierras de temporal y sin injerencia en los precios de mercado, por lo que ha predominado un escenario de pobreza. El documento se estructuró bajo la perspectiva crítica y para su análisis se utilizó una metodología de tipo hipotético deductiva. A partir de la información disponible de investigaciones realizadas sobre pequeños productores y datos oficiales, se pudo comprender los procesos en los que se desenvuelven las actividades de los campesinos en el mundo y, de manera específica, en Zacatecas. En este lugar la población campesina vive en localidades con menos de 2500 habitantes, por lo que son consideradas como poblaciones rurales. La precariedad en la que se desenvuelven ha implicado fortalecer y mejorar sus prácticas agropecuarias con el impulso de emprendimientos como las escuelas para mujeres y jóvenes rurales, mediante el acompañamiento a los productores impulsados desde el aparato gubernamental con el respaldo de la Organización de las Naciones Unidas para la Alimentación y la Agricultura (FAO, por sus siglas en inglés). La finalidad era fortalecer la unidad socioeconómica campesina como parte del apuntalamiento para su reproducción de subsistencia, sin transitar a la producción rentable y con ganancias. A pesar de las adversidades económicas y sociales de incertidumbre y precariedad, los campesinos se mantienen.

Palabras clave: precariedad, viabilidad, pequeña producción campesina, Zacatecas.

\section{Descriptores:}

P25 Economía urbana, rural y regional

R11 Actividad económica regional: crecimiento, desarrollo, problemas ambientales y cambios

Q01 Desarrollo sostenible

\section{Abstract}

The objective of this article is to expose the processes of reconfiguration of peasant society, to face precariousness and perpetuate itself as a segment of the population that presses wages with a downward trend, by adding to the growth of population surpluses, in a province of the north-central Mexico called Zacatecas. In this place, 4 out of 10 Zacatecans live in rural áreas. Furthermore, in 2007 there were 124861 small producers and by 2016 there were 255236 , mainly common landowners and community members who produce for their own consumption on temporary lands and without interference in market prices, for which a scenario of poverty has prevailed. The document was structured from a critical perspective and a hypothetical deductive methodology was used for its analysis. From the information available in research on small producers and official data, it was possible to understand the processes in which the activities of peasants take place in the world and, specifically, in Zacatecas. In this place, the peasant population lives in towns with less than 2500 inhabitants, which is why they are considered rural populations. The precariousness in which they develop has implied strengthening and improving their agricultural practices with the promotion of enterprises such as schools for rural women and young people, by accompanying producers promoted by the government apparatus with the support of the United Nations Organization for Food and Agriculture (FAO). The purpose was to strengthen the peasant socioeconomic unit as part of the underpinning for their subsistence reproduction, without moving to profitable and profitable production. Despite the economic and social adversities of uncertainty and precariousness, the peasants remain.

Keywords: Precariousness, viability, small peasant productions, Zacatecas. 


\section{Resumo}

O objetivo deste artigo é expor os processos de reconfiguração da sociedade camponesa, para enfrentar a precariedade e se perpetuar como um segmento da população que pressiona os salários com tendência de queda, ao se somar ao crescimento dos excedentes populacionais, em uma província do centro-norte do México, conhecida como Zacatecas. Neste local, 4 de cada 10 zacatecanos vivem em áreas rurais. Além disso, em 2007 existiam 124.861 pequenos produtores, passando para 255.236 em 2016, principalmente ejidatários e comuneros que produzem para consumo próprio em terras temporárias e sem interferência nos preços de mercado, pelo que tem prevalecido um cenário de pobreza. 0 documento foi estruturado a partir de uma perspectiva crítica e utilizou-se para sua análise uma metodologia hipotética dedutiva. A partir das informações disponíveis nas pesquisas realizadas com os pequenos produtores e nos dados oficiais, foi possível compreender os processos em que se dão as atividades dos camponeses no mundo e, especificamente, em Zacatecas. Neste local, a população camponesa vive em cidades com menos de 2.500 habitantes, razão pela qual são consideradas populações rurais. Pela precariedade em que se desenvolve a população, foi preciso fortalecer e aprimorar as práticas agrícolas, fomentando empreendimentos como escolas para mulheres e jovens rurais, ou iniciativas de acompanhamento a produtores, promovidas pelo aparato governamental com o apoio da Organização das Nações Unidas para a Alimentação e Agricultura (FAO, por sua sigla em inglês). 0 objetivo foi fortalecer a unidade socioeconômica camponesa como alicerce de sua reprodução de subsistência, sem necessariamente passar para uma produção lucrativa. Apesar das adversidades econômicas e sociais, e da incerteza e precariedade, os camponeses permanecem.

Palavras-chave: precariedade, viabilidade, pequena produção camponesa, Zacatecas.

\section{Introducción}

El presente artículo expone los procesos de reconfiguración de la sociedad campesina para enfrentar las condiciones de precariedad en las que se ven inmersos los integrantes de la unidad familiar ${ }^{1}$ o unidad socioeconómica campesina², de una provincia del centro-norte de México, llamada Zacatecas. La relevancia del análisis tiene como telón de fondo los estudios de diversos autores que hablan acerca de la desaparición de esta forma productiva, conformada por campesinos en las postrimerías de la década de los 70 e inicios de los 80 en México. La evidencia muestra que esta forma de producir persiste aun en contra de esos presagios, y en contraposición de la forma de acumulación que domina actualmente dentro del modo de producción capitalista, en el que prima la obtención de la máxima ganancia. A pesar de que este proceso ha generado condiciones adversas para esta unidad socioeconómica y sus integrantes, que implica vivir en condiciones de incertidumbre y precariedad, se mantiene mediante el empleo de una infinidad de estrategias de sobrevivencia

1 Unidad familiar: grupo de personas que integran la familia y están unidos mediante un común acuerdo empresarial.

2 Unidad socioeconómica campesina. Grupos pequeños de campesinos unidos con un propósito de común acuerdo empresarial. 
utilizadas según el entorno natural, sociodemográfico, económico y cultural, entre otros aspectos.

\section{Aspectos teóricos y conceptuales}

El andamiaje teórico utilizado en este documento se sustenta bajo la perspectiva crítica. El primer concepto o categoría parte de la conceptualización que se tiene del campesino o del pequeño productor minifundista, que ha prevalecido en los diferentes modos de producción por los que ha transitado la humanidad. Así mismo, la vinculación que este ente económico social mantiene al interior del modo de producción vigente, y que tiene como finalidad la acumulación derivada de una heterogeneidad de formas existentes en diferentes contextos, tiene que ver con la globalización.

Este proceso provoca infinidad de reajustes en las condiciones de producción y reproducción. En consecuencia, el segundo concepto está delimitado por la globalización, que adopta características específicas según el ámbito en el que se impulse. De igual forma, la globalización interviene en el desarrollo de procesos productivos bajo el mecanismo del desarrollo biotecnológico. El desenvolvimiento de la globalización en las diferentes partes del mundo muestra niveles diferenciados con una tendencia hacia la homogenización, tanto en el ámbito de las corporaciones agroindustriales como en la economía campesina.

El tercer concepto teórico está relacionado con la derivación lógica que procede al ser copados por el concepto de la globalización, que recae en los pequeños productores agropecuarios, expresada en la precariedad campesina como reducto permanente de la misma. Finalmente, encontramos las políticas públicas específicas impulsadas por el Estado, que proliferan para mantener una paz social acorde con las necesidades de la acumulación que permiten la refuncionalización y persistencia de los pequeños productores minifundistas; igualmente, la relación conceptual derivada permitirá mostrar las contradicciones de la vinculación que los campesinos mantienen con el modo de producción dominante.

\section{Metodología}

Teniendo en cuenta la anterior conceptualización, para el análisis de los pequeños productores campesinos del territorio zacatecano se utilizó un soporte metodológico de tipo hipotético deductivo (combina la inducción y la deducción). Es decir, se parte de la consideración de que la precariedad permite la viabilidad de la reproducción 
de las poblaciones rurales dedicadas a la producción primaria, que se sustenta en las investigaciones previas de este tópico, como una premisa general para sacar conclusiones del tema, como un caso particular. En ese orden de ideas, se analizan las investigaciones vinculadas, los datos del Instituto Nacional de Estadística y Geografía (INEGI), los censos de población, además de otros reportes generados por la Secretaría del trabajo y Previsión Social (STPS) y el Servicio de Información Agroalimentaria y Pesquera (SIAP).

Se advierte que el fenómeno de análisis es un problema real, que se ha constatado mediante el abordaje y estudio de casos específicos; en ese sentido, la revisión de la bibliografía es esencial, tanto como lo es el apoyo de la teoría para desarrollar este tema como proceso del conocimiento. A la par, se tomaron los resultados de una encuesta previa aplicada en localidades con menos de 2500 habitantes de los municipios de Mazapil, Fresnillo, Francisco R. Murguía, Pinos, Vetagrande, Pánuco y Concepción del Oro, elegidos por la relación que se tenía con los porteros y la disposición de los pobladores, mayores de 18 años, a compartir la información disponible en los tres años que duró el trabajo en campo. En estas comunidades se aplicaron 960 encuestas de pregunta cerrada y opción múltiple, con un apartado de observaciones que permitió tomar aspectos que no se expresan verbalmente, pero son observables.

Con los datos de las 56 preguntas de la encuesta se construyeron cuadros que sintetizan los temas contemplados para conocer su relación con la economía. Las representaciones se construyeron a partir de las actividades dentro y fuera del predio de sus integrantes.

\section{La unidad de análisis}

La provincia de Zacatecas está ubicado en el centro norte de México, posee una orografía accidentada, tres cuartas partes de sus tierras son semidesérticas y otras tienen fertilidad diversa, gracias a lo cual se pueden aprovechar para generar mercancías y productos que en el ámbito nacional ocupan los primeros lugares en compra por parte de los habitantes de la provincia. Los cambios económicos, sociales, políticos y culturales se explican por varios factores, entre los cuales vale la pena resaltar el agotamiento de la explotación minera en el siglo pasado y el impulso de esta actividad en la primera década del XXI, cuando se reactivó el sector gracias al descubrimiento de nuevos yacimientos. Esa reactivación también involucró la política agraria y ganadera, empresarial y comercial.

Con base en fuentes oficiales, se puede afirmar que el campesinado del estado de Zacatecas prevalece, ya que actualmente 4 de cada 10 zacatecanos viven 
en la zona rural. Según el Censo General de Población y Vivienda 2010, el estado de Zacatecas tenía una población de 1.477 .915 habitantes, compuesto por 757.383 mujeres y 720.532 hombres. Al hacer una comparación con respecto al año 2000, se observa un crecimiento en la población total de 7,27 \%. Es pertinente destacar que la población femenina sigue siendo mayor a la masculina. Para 2015, según el Instituto Nacional de Estadística y Geografía (INEGI, 2017), en el Estado existía una población de 1.579.209 habitantes, conformado por 808.841 mujeres y 770.368 hombres; es decir, hubo un crecimiento anual más acelerado de 1,37 \%, superior a lo que representó el crecimiento de 2000 a 2010 de 0,73 \%. En cuanto al número de productores agropecuarios, la misma fuente señala que para 2007 existían 124.861 pequeños productores, de los cuales 106.661 eran ejidatarios y comuneros. Esta cifra se dispara en 2016, al sumar 255.236, principalmente ejidatarios y comuneros que producen para el autoconsumo en tierras de temporal y sin injerencia en los precios de mercado, predominando un escenario de pobreza ante la pulverización de la estructura de la tenencia de la tierra (INEGI, 2017).

En esta población rural destaca el número de mujeres, por encima de los hombres, dedicadas a diferentes actividades, cuyas formas específicas de producción se inscriben dentro de una relación formal (relación capital-trabajo) e informal o por su cuenta. Además, se hace evidente que la migración sigue jugando un papel importante en el mantenimiento de la reproducción socioeconómica de la unidad campesina. En esta zona se realizan un sinnúmero de actividades como la producción de granos básicos, hortalizas, la cría de ganado de forma extensiva e intensiva y la extracción de minerales.

El Estado se destaca por ser productor prominente de frijoles claros, pintos y negros que aportan más del 50 \% al consumo nacional, al igual que la producción de chile, zanahoria, cebolla y frutales como la guayaba, el durazno, la uva, la tuna, entre otros (INFOSIAP-SAPARPA, 2017).

La cría de ganado ocupa el segundo lugar, a nivel nacional, gracias a la producción de carne en canal de caprinos o cabritos. Así mismo, la producción de ovinos ocupa el quinto lugar, mientras que el sexto lo ocupa la producción de leche de caprino (INEGI, 2013). En 2016 se incrementó fundamentalmente la producción de carne en canal de ese ganado, pero también se observó un claro repunte en la producción porcina y bovina, y en la de leche y miel (INFOSIAP-SAPARPA, 2017). En cuanto a la producción minera, destacan la extracción de oro, plata, plomo, cobre y zinc, cuyo incremento entre 2006 a 2015 se ha disparado en 2579 \%, 169 \%, 357 \%, 233 \% y 176 \%, respectivamente (INEGI, 2017), (tabla 1). 
Tabla 1. Zacatecas: volumen de la producción minera en toneladas (2006-2015) *

\begin{tabular}{lcccc}
\hline $\begin{array}{c}\text { Producción / } \\
\text { Año }\end{array}$ & $\mathbf{2 0 0 6}$ & $\mathbf{2 0 1 5}$ & Crecimiento \% & $\begin{array}{c}\text { Crecimiento \% } \\
\text { anual }\end{array}$ \\
\hline Oro & 144100 & 3716031 & 2579 & 516 \\
\hline Plata & 147760100 & 249485500 & 169 & 34 \\
\hline Plomo & 4635900 & 16534800 & 357 & 71 \\
\hline Cobre & 1820100 & 4238100 & 233 & 47 \\
\hline Zinc & 19242200 & 33864900 & 176 & 35 \\
\hline
\end{tabular}

Fuente: INEGI (2017) y Panorama minero del Estado de Zacatecas. Servicio Geológico Mexicano; Secretaría de Economía 2018. *La cantidad de oro y plata es en kilogramos.

\section{La pequeña producción campesina}

Los campesinos o pequeños productores minifundistas han sido analizados desde diferentes cimientos teóricos, tales como: la perspectiva de aversión al riesgo, la postura crítica, utilización de técnicas multivariantes, desarrollo rural, estructuralismo o desde la posición histórica lógica, entre otros. De estas posturas, la que tiende a dominar es la crítica. Todas, desde su particularidad, se sustentan en una noción de lo que la categoría de campesino mantiene como parte de sus atributos a lo largo de la historia. De entrada, se debe dejar en claro que el campesino no pertenece a ningún modo de producción por los que ha transitado la humanidad, aunque su concreción se hace presente desde el esclavismo hasta el socialismo.

Teniendo en cuenta lo anterior, y retomando a Llambi (1991) y Kay (2001), Paz (2006) afirma que cada campesino es construido a partir de los periodos de acumulación, como parte de la funcionalidad del proceso y asumiendo roles específicos en cada nivel de desarrollo de la acumulación. En ese sentido, se puede señalar que el concepto de campesino nació antes de la existencia del capitalismo, de modo que esta relación social y forma de organización del trabajo y de la producción puede ser familiar, comunitaria, asociativa o cooperativa, pero nunca capitalista. El campesino vive su tiempo y vivió todos los tiempos: en las sociedades esclavistas, feudales, capitalistas y socialistas. Es un sujeto histórico perenne que lucha para ser él mismo. En la medida en que los sistemas quieren destruir el campesinado, él reacciona para reproducirse con dignidad (Monçano, 2014).

En esa tesitura, y bajo el análisis del territorio argentino, se señala que el concepto de campesino permite no solo interpretar analíticamente las características y dinámicas socioeconómicas que lo constituyen, sino dar cuenta del horizonte político implícito -y explicito- en las modalidades de relacionamiento históricamente 
conflictivo, subalternizado, y por tanto antagónico con otras clases del campo; así como su particular relacionamiento con la naturaleza, no basada en su mercantilización (Hocsman, 2014). Los campesinos en el mundo no fueron producto del modo de producción vigente. Estos fueron adoptados en función de sus necesidades de acumulación, en su tránsito adoptaron y adoptan formas multiformes, pero no dejan de ser campesinos como parte de la estructura agraria que prevalece en el mundo, con matices diferenciadores tenues sin adoptar formas estructurales profundas. Por ello, la definición de estos entes es diversa y está en función de su relación con la dinámica del proceso de acumulación dominante.

Existen definiciones como la de la Cepal, que señala que la economía campesina es una unidad familiar con múltiples actividades y con diversas fuentes de ingreso y combinaciones, su rasgo principal es el de valorizar sus recursos y activos para conseguir su reproducción (Cepal, 1999). En cambio, algunos ubican al campesino como jornalero y agente productivo fundamental para generar cohesión interna y participar activamente en la solución de sus necesidades (Arroyo, 2001). Otras posturas señalan que la economía campesina es considerada como una unidad socioeconómica que funciona en sentido contrario al resto de la economía, porque produce para el autoconsumo, emplea mano de obra familiar, su producción es temporal y recurre a otros trabajos para disponer de recursos suficientes para sobrevivir (Bartra, 2006). Por lo tanto, el campesino es considerado como una bacteria aeróbica facultativa que aprendió a sobrevivir en un medio sin capital, donde empresas capitalistas mueren (aeróbicas por excelencia), el campesino sobrevive mediante estrategias productivas, sociales, culturales y económicas (Paz, 2006).

Para Herrera (2013), los campesinos son aquellas personas que articulan su trabajo agrícola de subsistencia en sus comunidades, durante una parte del año, con el que realizan como trabajadores fuera de la parcela. En términos generales, es el que produce para el autoconsumo al utilizar una estrategia diferente a la capitalista para allegarse lo que necesita para su sobrevivencia y la de su familia (De Luna, 2014). Por su parte, Ceceñas y Morales (2015) señalan que la economía campesina, que se distingue en algunas partes del territorio zacatecano, está conformada por productores que tiene predios menores a cinco hectáreas, cuentan con muy baja tecnología para desarrollar su producción y su agricultura de autoconsumo prevalece como una estrategia de seguridad alimentaria. Marisol Cruz (20017) afirma que el campesino es producto de la revolución, en cuyo caso el Estado le da una función determinada en la forma de productor de autoconsumo y actor que impulsa su propio cambio de una sociedad reajustada a las condiciones y necesidades del sistema económico. Akram-lodhi (2009) define al campesino como el trabajador agrícola cuyo sustento 
depende del acceso a la tierra, ya sea propia o rentada; usa su propio trabajo y el de la familia para hacerla producir (Noriero y Massieu, 2018). La óptica oficial los considera como un sector social altamente vulnerable, sujeto a las políticas de asistencia social orientadas a superar la pobreza y prácticamente los deja fuera de los programas de apoyo productivo (Orozco y López, 2007).

Noriero y Massieu (2018) señalan que el destino de los campesinos era la proletarización y la destrucción de su economía de productores directos en el capitalismo, o si existían vías de existencia de la pequeña producción campesina familiar, se inserta sujeto a sus condiciones sin dejar de considerar que esta funciona de forma distinta a la relación capital-trabajo asalariado. Independientemente de la perspectiva o de las diversas características, el aspecto que debe prevalecer como parte relacional del despliegue de las actividades del campesino es la tierra. Su relación permite reflejar la condición que establece con el mercado en un momento histórico determinado. Por lo tanto, la relación que mantiene con los niveles de acumulación, en el modo de producción dominante, muestra el desgaste y deterioro de su relación; sin embargo, a pesar de este deterioro persiste su vínculo, independientemente de la visión reduccionista, para ubicarlo en un contexto progresivo hacia su desaparición mediante el proceso de proletarización.

\section{El modelo de acumulación}

En el desarrollo del capitalismo se han adoptado diferentes modelos de acumulación; además, el nacimiento de cada uno de estos modelos supone la muerte o desaparición del otro, mediado por una crisis de acumulación (De Luna, 2017). Esta representación es un movimiento dialéctico, que no es una mera repetición de acontecimientos sino de modificaciones profundas derivadas de transformaciones internas que emergen como nuevos mecanismos ordenadores. La forma de mayor representatividad para el cambio adoptado dentro del modo de producción capitalista es el de la crisis. Una ruptura interna del proceso de acumulación, que tiene como objetivo la ganancia, es trastocada. El núcleo de la relación que genera el excedente en una simbiosis capital-trabajo se ha desdibujado y la crisis se hace patente; con ella, emergen otros mecanismos que dan forma a un proceso de acumulación bajo los cimientos del anterior modelo.

Bajo esa perspectiva, la composición de capital global sufre modificaciones dado que los capitales singulares, invertidos en determinado ramo de la producción, presentan una composición que difiere de unos a otros en mayor o menor medida; así, los que tengan mayores condiciones sobrevivirán hacia una nueva modalidad de 
acumulación, bajo una concentración y centralización del capital (Marx, 1982). Este proceso irrumpe en América Latina en la década de los 70, teniendo como trasfondo el rompimiento de Estados Unidos con el pacto de Breton Woods y la crisis mundial del petróleo (Mueller, 2009), que obligó a los países periféricos, entre los cuales se encontraba México, a la adopción de un proceso de desregulación económica. De manera diferenciada, los países latinoamericanos incursionaron en el modelo de acumulación que hoy domina. Desde sus inicios, este proceso de globalización en México, que le permitió entrar al Acuerdo General de Aranceles y Comercio (GATT) en 1986, ha sido violento por la forma indiscriminada en que se abrieron las fronteras y la coherencia en los acuerdos comerciales (Espinosa, et al., 2009).

A pesar de lo anterior, este pudo haber sido un proceso menos violento, si las bases de la globalización hubiesen incluido un desarrollo paulatino desde abajo; es decir, con la implementación de una forma de neoliberalismo más cálida y más humana que no cercenara de tajo los lazos sociales, con lo cual se habrían podido manejar mecanismos más tersos y justos, internos y externos, para contrarrestar el dominio de una minoría sobre la mayor parte de la riqueza en el mundo (Alva, Lins y Gordon, 2015). Sin embargo, como dependen uno del otro, los procesos de mundialización no se pueden hacer por separado. Mientras desde arriba puede encontrarse el beneficio de hacer transacciones en la sombra (evasión de impuestos, lavado de dinero, fuga de capitales, producción ilegal), desde abajo se busca la supervivencia, la integración económica y el ascenso social (Alva, C. et al., 2015: 187).

En general, se puede estar de acuerdo en que es a partir de los años 80 que se inicia un proceso hacia la inserción de las economías a la globalización, la cual es vista como una transformación de apertura comercial e integración a la economía mundial, mediante reformas de menor intervención del Estado en actividades productivas, apertura comercial externa, desregulación económica y equilibrio en la cuenta pública. En México, el Tratado de Libre Comercio de América del Norte (TLCAN) es la consolidación de este proceso (CEPAL, 1999). Este curso que adopta nuestro país implica un reacomodo singular al concatenar aspectos internos y externos que influyen de diferente manera en una economía polarizada en sus sectores económicos, siendo el agropecuario el más castigado. Por un lado, se observa la retirada del Estado en ámbitos de la producción económica interna y, por el otro, la dinámica que imprime la apertura externa que se compagina con el incremento de la deuda y la crisis petrolera gestada en el segundo lustro de esta década.

En ese sentido, se afirma que la modificación del proceso de desarrollo en los 80 propició la concentración del capital de una manera más acelerada. Las características que adquiere la evolución, lo presentaron como un modelo polarizante que 
excluye a los que no pueden competir en el mercado, lo que permite la existencia de dos posturas en torno a la evolución del sector agropecuario en México: los que generan un empuje moderno y dinámico, vanguardista, pujante, con perspectivas positivas para el intercambio con el exterior; y los que conforman aspectos de atraso, ineficientes y excluidos de la globalización. Las características intrínsecas que presentan ambas visiones, a pesar de ser contrapuestas, son complementarias e inherentes al desarrollo de una economía capitalista subdesarrollada incapaz de ofertar los empleos necesarios y remunerados de manera decorosa (C de Grammont, 2010).

El capitalismo de la globalización muestra contradicciones en cuanto al rol campesino; por un lado, descalifica a la producción campesina y, por el otro, no le genera un contexto económico y social capaz de absorberla como acceso formal al mercado de trabajo. El proceso de globalización presenta lógicas comunes, a veces repetitivas y generalizables, como lo es la desaparición de la pequeña producción en el mundo agrario más desarrollado; pero es cierto también que existen singularidades en los territorios donde la penetración del capitalismo es aún muy limitada. Entender dicha cuestión permite analizar los procesos de transformación del campesinado como procesos de reacomodamiento y de refuncionalidades dentro de sus estrategias, en los cuales no necesariamente la lógica de acumulación capitalista conducirá irreversiblemente a la descampesinización del sector (Paz, 2006).

Ahora bien, las adversidades que trajo consigo la retirada del Estado desarrollista y la incursión del mercado como nuevo garante de la distribución de los beneficios, ha impulsado una concentración de la tierra y otros recursos, con claros matices negativos para la economía campesina. "El desarrollo tecnológico aplicado en la agricultura ha generado niveles mayores de explotación a través de su precarización" (Kay, 2016, p. 2). En consonancia con lo anterior, pero teniendo en cuenta el contexto mexicano en el que está inmersa la economía zacatecana, se señala que la imposición de la globalización y las políticas neoliberales impulsadas, sumergen a los campesinos tlaxcalteños en realidades que afectan su reproducción (Noriero183-85). La realidad muestra un colapso de las actividades agropecuarias que han hecho aún más difíciles las condiciones de sobrevivencia de la mayoría de los productores campesinos minufundistas, en contraposición con un limitado número de productores que adoptaron el proceso productivista como lógica. Estos caminos bipolares, por los que transita el sector agropecuario, son apuntalados por una política económica implementada a ultranza en la que la participación de los Estados mexicanos, bajo una dirección nacional, poco o nada pueden hacer para modificarla, lo que profundiza las condiciones de precariedad en las que se desenvuelven estos productores 
minifundistas y fortalece a un puñado de productores con capacidad para competir en los mercados de diferente tipo.

\section{El sendero de la precariedad}

En las últimas cuatro décadas, las condiciones vividas por el campesino o la economía campesina en México han mostrado los estragos reducidos a condiciones de pobreza y expulsión de sus territorios de manera permanente. El proceso de los 80 se caracteriza por el retiro paulatino del Estado ante el desconcierto de los productores rurales minifundistas y la penetración paulatina del mercado, mediante la incipiente globalización. A partir de la segunda mitad de la década de los 90, el proceso de reconfiguración de este campesino, frente a las condiciones impuestas por el capital en México, adquiere mayor adversidad a pesar de su lucha constante por mantener condiciones favorables para su reproducción. El pertinaz mecanismo de la ley de acumulación del capital hace mella en las fragmentadas condiciones de la mayoría de la población rural mexicana. La implementación del desarrollo tecnológico, en la relación capital trabajo de infinidad de procesos productivos, conllevó influencias diversas en la gama de los productores mexicanos. Su comportamiento no escapa a

la ley del modo capitalista de producción que, con su desarrollo, se opera una disminución relativa del capital variable en relación al [sip] capital constante, y de ese modo en relación con el capital global puesto en movimiento [...] mediante el creciente empleo de maquinaria y de capital fijo en general, el mismo número de obreros transforma en productos mayor cantidad de materias primas con menos trabajo, lo que corresponde a un abaratamiento del producto. (Marx, 2009: 270-271).

Se observa que la actividad productivista influye en el abaratamiento de las mercancías producidas y, a la vez, desplaza fuerza de trabajo mediante la modernización de los procesos productivos; esta situación aumenta el desempleo y disminuye de manera permanente los niveles salariales. El ajuste estructural y la crisis persistente han reducido los salarios reales, lo que es negativo para las familias de campesinos y acelera la búsqueda de estrategias que permitan su reproducción de vida, como la economía informal en un pequeño comercio, microempresas, autoempleo, artesanías y tareas domésticas (Cepal, 1999). La situación no se da de manera mecánica hacia todos los sectores de la economía. En México, es en el terreno agropecuario donde las condiciones se agudizan con mayor fuerza debido a dos acontecimientos 
importantes: el fin de la repartición de la tierra, impuesto por la modificación del Artículo 27 constitucional y la firma del Tratado de Libre Comercio con América del Norte (TLCAN). "se trata de los acontecimientos más importantes en el desarrollo de la actividad campesina del país, que trajo consecuencias lógicas en los distintos entes sociales que se organizaban bajo la bandera de la lucha por la tierra" (Arteaga, 2019: 111). Estos dos eventos, aunados a la aplicación de los lineamientos implementados por la regulación económica impulsada en la década anterior, fomentaron la consolidación de un dualismo estructural productivo agropecuario que ha generado una profundización en la desigualdad de los polos opuestos.

De esta forma, se ha producido una nueva división del trabajo: los grandes productores incrementaron su producción sobre la base de la tecnología avanzada, el uso intensivo de químicos, reduciendo costos de producción e incentivando la agricultura por contrato. Los pequeños productores han sido marginados del proceso de producción, su papel es el de aportar alimentos baratos para el mercado interno y fuerza de trabajo asalariada, como lo señala Teubal (1993; 2002), (Tapella, 2004). Por un lado, se observa un sector de productores pujante que se ha vinculado a la mundialización de la economía, mediante la implementación de paquetes tecnológicos de vanguardia, en los que predomina el monocultivo sustentado en semilla y tecnificación con lo cual se reduce la cantidad de fuerza de trabajo (Hocsman, 2014). Por el otro, se observa un conjunto de productores cada vez más desprotegidos y a merced de las leyes del mercado que los excluye hacia ámbitos que se respaldan en el autoconsumo, como parte de su reproducción como campesino. En ese sentido se reafirma la existencia de un campo polarizado y desarticulado con una mayoría de productores ineficientes, escasamente vinculados al mercado, y una minoría de empresas eficientes integradas a las cadenas productivas.

Este modelo no es capaz de crear los empleos necesarios, ante lo cual los campesinos que producen solo para el autoconsumo no están en transición hacia su proletarización, sino que se reproducen como unidad pluriactiva (C de Grammont, 2010). Su lógica productiva no es capitalista, sin embargo mantiene un vínculo con esta como pequeños productores subsidiarios o sobrepoblación relativa, pero no es permanente y eso acelera su desarticulación, puesto que -en la medida en que desaparece la industria a domicilio, se usurpa la propiedad comunal y aparecen los cultivos a gran escala-, aumenta cada vez más el tiempo de trabajo invertido para su subsistencia. En consecuencia, cuando el campesino ya no es funcional para la economía capitalista, tenderá a refugiarse en el autoconsumo conservando vínculos esporádicos con ella (Figueroa, 2005). Como la producción agropecuaria no es favorable para millones de campesinos, buscan la mejor opción para allegarse lo necesario 
para sobrevivir y reproducirse; en medio de salarios marginales, para aquellos que tienen la suerte de ser contratados, se incrementa la dimensión de la pobreza. Pero siguen ahí, en medio de la precariedad, con la esperanza de insertarse y vincularse a las constantes modificaciones de la acumulación del capital. Por lo pronto se les presentan dos alternativas, ante las nulas expectativas agrícolas de competencia con los medianos y grandes productores: 1) producir lo necesario para su autoconsumo y buscar, mediante mecanismos del entorno inmediato, su inserción a puestos precarios (asalariados y no asalariados) dando vida a la pluriactividad, 2) optar por la migración interna o externa de manera pendular. Con el tiempo, cualquiera de las dos alternativas hará estragos en su desvinculación territorial inmediata para ser presa de la concentración y centralización de la tierra y del capital, que inexorablemente recorren el territorio nacional e internacional como proceso dominante.

Con el fin de preservar las condiciones de producción del núcleo familiar de reproducción, para algunos campesinos la opción más viable será la migración; para otros, la de rentar o vender la tierra para insertarse como jornaleros estacionales. En ese sentido, la diversidad de alternativas a las que pueden recurrir están determinadas por el entorno inmediato, incluso más allá de las fronteras de la comunidad, el estado o el país. Al respecto, Herrera señala que "en diversas partes del mundo, el campesino subsiste en condiciones económicas y sociales extremadamente precarias, que obligan a sus integrantes a migrar, tanto dentro de sus propios países como hacia afuera de ellos" (2013, p. 6).

Los campesinos migran buscando alternativas de subsistencia como jornaleros o proletarios en las ciudades. Allí, desarrollan actividades por cuenta propia, por ejemplo, se desempeñan como lavacoches, artesanos independientes o en la esfera doméstica como población absoluta, ya que no se proletarizan (Figueroa, 2005). En síntesis, la estrategia de diversificar las actividades permite mantener el vínculo entre la reproducción de la fuerza de trabajo y supervivencia familiar y la lógica del mercado, dado que se ha conformado una incipiente cadena productiva que ha permitido la supervivencia de los productores, a pesar de que la migración sigue siendo la estrategia de mayor relevancia para la sobrevivencia (Orozco, 2007).

A la par de estas consideraciones, se pueden mencionar algunos aspectos que muestran que el productor minifundista persiste y se mantiene, a pesar de los lineamientos señalados que tienden a desaparecerlo de manera permanente. En esos términos, se puede inferir que la precariedad en la que se encuentran los productores agropecuarios minifundistas, como consecuencia de la política económica implementada, encierra los mecanismos utilizados para mostrarlos como productores ineficientes y atrasados, en la medida en que los beneficios otorgados 
por la implementación de las políticas públicas, en general, están dirigidas a quienes tienen mejores condiciones para participar en los diferentes ámbitos del mercado. Esos mecanismos están enmarcados dentro de los lineamientos generales del modo de producción capitalista. En él se encierran esos mecanismos, en tanto que en su interior se desenvuelve la cuestión agraria prevaleciente como parte de la lucha de contrarios. La cuestión agraria nació de la contradicción estructural del capitalismo, que produce simultáneamente concentración de riqueza y expansión de la pobreza. En esa diferenciación prevalece la sujeción y la resistencia del campesinado en la lógica del capital.

El capital se realiza a partir del desarrollo de su propia relación social, destruye y recrea el campesinado, a partir de su lógica y principios; pero también se desarrolla en la creación y en la recreación del campesinado (Meillassoux, 1979; Bartra, 1982; Hocsman, 2014). A pesar del embate que sufre este cúmulo de productores agropecuarios, se presenta como una alternativa firme de generar mejores condiciones de vida para la población del planeta, en la medida en que se afirma que no hay una solo vía de desarrollo capitalista y la relación capital-trabajo en la agricultura dista mucho de ser homogénea, lo que hace que subsista la pluriactividad y no la desaparición de los productores minifundistas (Noriero y Massieu, 2018).

Reconocer al campesinado como un modelo estratégico de desarrollo de la agricultura, es necesario para superar el mito de las commodities como condición para acabar con el hambre. Además, el campesinado genera más puestos de trabajo que el agronegocio, promoviendo las condiciones necesarias para el desarrollo sustentable (Monçano, 2014); así, por ejemplo, a partir de la misma fuente sobre datos aportados, se puede concluir que produce el $42 \%$ del valor de la producción y genera el $61 \%$ de los empleos del sector agropecuario. En ese sentido, la economía campesina minifundista persiste y se mantiene en condiciones diversas vinculada a la vorágine capitalista de acumulación.

\section{El papel del Estado}

La actividad que el Estado realiza en el modelo de acumulación capitalista neoliberal es brindar las condiciones de reproducción de quienes participan en su territorio. En el ámbito agropecuario, al que pertenecen los integrantes de nuestro objeto de estudio (pequeños productores minifundistas o campesinos), debe mantenerlo acorde con la política económica implementada a nivel nacional. La política productivista del monocultivo, regida por las leyes del mercado, tiene la supremacía de los beneficios utilizados para mantener avante el proceso de acumulación. De esta forma, quien no cumple con las condiciones de modernización apropiadas para la competencia 
nacional e internacional queda excluido de los beneficios, básicamente relacionados con créditos e insumos agropecuarios.

A pesar de lo anterior, el Estado no se puede desentender de las condiciones en las que se desempeñan los productores que no alcanzaron a beneficiarse de la política general. En ese sentido, los productores minifundistas que no alcanzaron a recibir esos beneficios se aprestan a recibir otros de carácter asistencial que les permitan preservar las condiciones de reproducción mínimas, para seguir jugando un determinado papel en el proceso de acumulación. Son productores que, en las condiciones de acumulación prevaleciente, fueron excluidos del mercado ante las deficiencias de producción en sus predios o fincas rurales. El proceso lógico de su desempeño será la expulsión de sus parcelas y la consecuente proletarización. Por lo tanto, es en ellos donde la influencia de la política pública específica hace énfasis para acelerar el proceso o hacerlo más lento. Para ello, se vale de acciones deliberadas cuyo propósito es mantener esas condiciones o no hacer nada para que avancen de manera irremediable hacia la quiebra. Además, su aceleración será mayor o menor con la intervención de la política pública en ámbitos de la producción, distribución y cambio; y ante la ausencia de ellas, debe buscar alternativas que posibiliten resarcir los aspectos negativos en esos ámbitos, mediante la sustentabilidad natural y social (De Luna, 2014: 351).

Regularmente, la intervención se realiza fundamentalmente en aspectos y derechos de carácter económico-social. Desde la implementación del modelo de acumulación, en la década de los 80, hasta la fecha, este proceso ha incluido acciones deliberadas del Estado para mantener las condiciones señaladas en los campesinos minifundistas mexicanos. En términos generales, es algo similar a lo que proponen, como una de sus políticas fundamentales, organismos internacionales como el banco Mundial (BM), el Fondo Monetario Internacional (FMI), el Banco Interamericano de Desarrollo (BID), la Organización Mundial de Comercio (OMC), la Organización de las Naciones Unidas para la Alimentación y la Agricultura FAO, entre otros: monitorear las condiciones en las que se desenvuelve la vida de los que menos tienen, con la intención de implementar mecanismos que posibiliten detener la inanición de la "gallina de los huevos de oro". Ante el desastre que deja el modelo de acumulación prevaleciente, estos organismos y el Estado nación deben implementar estrategias que permitan mantener las condiciones mínimas de reproducción de estos entes y sus familias.

Desde los noventa se impulsó por el Banco Mundial los fondos de inversión social (FIS) en pequeños proyectos anti cíclicos, que ante la persistencia de la pobreza se convirtieron en proyectos de largo plazo y se 
orientaron a incorporar a los pobres en el proceso de producción. Al igual que en muchos países implementaron los fondos de inversión para mitigar el impacto de las políticas de ajuste, reducir la pobreza y frenar las migraciones rurales (Tapella, 2004: 676-86).

De esta forma, si el Estado se retiró del ámbito de la producción de bienes y servicios de todo tipo, entre los que se encontraban los productos estratégicos, la situación de vida de sus moradores empeoró de manera paulatina hasta el margen de la inanición. Es en ese proceso, y en mayor medida en ese límite, como se utiliza la maquinaria del Estado y de los organismos señalados. Ese mecanismo mostrará la contradicción entre los Estados que, por un lado, abandonan el principio de bienestar al permitir leyes laborales que reproducen la pobreza y, por el otro, tratan de mitigar esta pobreza con transferencia de recursos a través de políticas sociales de carácter asistencial (Valdez, 2015: 48).

Las políticas públicas implementadas, en su gran mayoría, estarán dirigidas hacia productores y sus familias, con el fin de atender las condiciones de deterioro en sus derechos humanos y universales, o simplemente el derecho a una vida digna. Por esta razón, renglones como la pobreza, la migración, el hambre, la equidad de género; junto con derechos sociales como la salud, la vivienda, la educación, entre otros, son rubros atendidos por ellos, en menor o mayor medida, para preservar, al final de cuentas, las condiciones de ganancia al capital. Ese objetivo (el de la ganancia) tiene que ser cuidado, de tal forma que es necesario que la fuente de donde fluye (población específica) esté en óptimas condiciones para integrarse a sus actividades en un proceso productivo determinado. Esta situación, sin embargo, posee límites de carácter natural y lógico que no permiten un proceso terso y sin alteraciones, lo cual limita su radio de maniobra por parte del Estado, pero también por parte de los organismos que toman las decisiones y que se ven limitados o rebasados.

En la relación capital-trabajo, que establecen los integrantes del proceso productivo, es el segundo (el trabajo) en el que se manifiesta un deterioro de manera paulatina, dado que es trastocado por la ley inmanente de la composición orgánica del capital, en la medida en que su lógica implica una composición menos de trabajo variable frente al capital constante. Esto hace que, en un tiempo determinado, sea rebasada la cantidad de personas que engrosan los niveles de desocupación, pues no serán absorbidas para desempeñar una actividad formal en ese proceso, lo que las lleva a buscar otras alternativas fuera de él, es decir, en la informalidad.

Para evitar que esto ocurra se necesitan programas de fomento generalizados y de largo plazo. Los programas actuales son pequeños y múltiples, además no 
son adecuados para responder a la población que lo requiere, pues presentan una fragmentación de la intervención gubernamental. Esta visión oficial implica el apoyo en función de la eficiencia. En consecuencia, es pertinente considerar a los campesinos como actores privilegiados del desarrollo, mediante políticas públicas adaptadas, coherentes y de largo plazo, que propicien también el desarrollo de pequeñas agroindustrias localizadas para fortalecer el mercado local, con lo cual se obtiene la seguridad alimentaria a través de una agricultura social y ecológicamente sustentable (C de Grammont, 2010). No obstante, lo que se percibe en algunos lugares de la economía zacatecana, es que los apoyos directos otorgados mediante programas como Procampo o diésel agropecuario, solo se convierten en un paliativo de subsistencia productiva (Reyes, 2009) y muestran las limitaciones de los productores de frijol del municipio de Sombrerete, debido a restricciones en la producción y la comercialización e ineficiencia de las políticas públicas (Ceceñas, 2015).

Para enfrentar la situación de pobreza de millones de campesinos minifundistas, producto de la herencia neoliberal, el Estado y organismos internacionales como la FAO implementaron el Proyecto Estratégico de Seguridad Alimentaria (PESA), que inició en México como fase piloto en 2002 (Muñoz, 2014; Gimante, Muñoz y Acevedo, 2018). Para 2011 este proyecto había logrado beneficiar a más de 180.000 familias, mediante una inversión de $\$ 2.550 .000$ pesos (Torres, Herrera, Vizcarra y Lutz, 2015). El financiamiento de este programa ha pasado de $\$ 561.000 .000$ pesos en 2007 a \$3.017.000.000 en 2015, además de representar un programa nacional al desarrollar actividades en 24 estados de la república mexicana (Gimante, et al. 2018). En Zacatecas, para el mismo año, según la Secretaría de Agricultura y Desarrollo Rural del Gobierno de México, se benefició a 9.000 familias (SADER, 2015). Para el 2018, según el Gobierno de Zacatecas (2018), el PESA operaba en 48 municipios y atendía con desarrollo y capacidades a 84.000 unidades de producción familiar, a través de la implementación de cocinas ecológicas, productos para el autoconsumo, proyectos holísticos, agricultura de conservación; así como captación de agua con presas, ollas de agua y bordos, mediante el acompañamiento de 13 agencias de desarrollo local.

De manera específica, el PESA mantiene áreas de acción que tienen que ver con el fortalecimiento de las condiciones de vida de las familias campesinas más necesitadas, en cinco aspectos de importancia: hogar saludable, traspatio, milpa, cadena productiva local y diversificación productiva. Sus ejes primordiales son la nutrición, el manejo de agua y suelo, las finanzas y el desarrollo organizacional (Muñoz, 2014). De esta forma se mantienen programas para pequeños productores, bajo el componente: "Arráigate joven - impulso emprendedor", cuyo objetivo es incrementar la disponibilidad de alimentos y fomentar, como su nombre lo indica, el arraigo de jóvenes en las 
comunidades rurales. El componente: "El campo en nuestras manos", busca incrementar la disponibilidad de alimentos mediante el aumento de la producción agropecuaria acuícola y pesquera de las mujeres que habitan zonas rurales y periurbanas, a través de apoyos y paquetes de huertos y módulos familiares de gallinas y conejos para autoconsumo, activos y desarrollo de capacidades (Cámara de Diputados, 2018).

A pesar de estos esfuerzos, las condiciones de los pequeños productores agropecuarios no se han modificado sustancialmente. La desigualdad y pobreza existente permiten entrever las condiciones de precariedad en las que se desenvuelven. Lo anterior permite señalar que las inversiones que se hacen, cada vez mayores, en estos programas, no son argumentos para seguir aumentando el presupuesto con una evidencia hacia la disminución de la pobreza, el hambre y la desnutrición (Gimante, et al. 2018). En contraposición, lo que se observa es que los programas de este tipo no están encaminados a resolver los problemas estructurales de estos productores, más bien sirven como paliativos para vivir en precariedad sin desaparecer, al fomentar de igual forma el capital político (Torres, et al. 2015). De ahí el señalamiento de la participación de los organismos internacionales en la realización de limpieza de los desastres económicosociales y ambientales, generada por el modelo neoliberal.

\section{Las condiciones de los productores zacatecanos}

A los pequeños productores se les encontró realizando diferentes actividades tanto en sus parcelas como en la calle, en algún jardín, en la escuela o en sus casas. Los resultados se muestran en cuatro variables relevantes, cuyas aportaciones permiten evidenciar aspectos de la persistencia y precariedad de los pequeños productores o campesinos.

Para mencionar algunos datos obtenidos de la encuesta, se puede mencionar que, del total de los encuestados, el 36,5 \% correspondió a hombres y el 62,95 \% a mujeres. Esta disparidad, a favor de las mujeres, se explica por la hora de aplicación del instrumento (entre 10:00 a.m. y 3 p.m.), periodo en el que una parte significativa de los barones se encontraba en las parcelas más retiradas del núcleo poblacional de la comunidad. Ahora bien, con respecto a las edades, el 13,2 \% corresponde a personas que tienen entre 18 y 25 años; el $11 \%$ a personas que tienen entre 26 y 30; el mayor porcentaje se ubica en personas que tienen de 31 a 45, con el 31,1\%; el porcentaje de menor representatividad lo tiene el $9 \%$ de la población encuestada; finalmente, el $12,5 \%$ corresponde a personas de 46 a 50 y el $23,6 \%$ a personas de 56 años. 
En relación con el nivel educativo, el de mayor representatividad corresponde a las personas que no tienen ningún nivel de formación académica, que corresponde al $52,3 \%$. Le siguen las personas que no tienen terminada la secundaria: 18,4\%. Aquellos que tienen la secundaria terminada: 8,3 \%. Posteriormente, encontramos porcentajes similares entre aquellos que tienen primaria terminada y los que poseen estudios profesionales: 5,8 \%. Luego encontramos a los que tienen la preparatoria terminada: 4,3\%. Personas que tienen la secundaria inconclusa: 2,4\%. El 2,1 \% corresponden a personas que tienen otros estudios y finalmente encontramos a los que tienen la preparatoria inconclusa: 1,4\%.

Si agrupamos la población con niveles de escolaridad ${ }^{3}$ que pudieron acceder a un empleo en condiciones favorables, solamente representaría el 12,2 \%. En otras palabras, el porcentaje de mayor relevancia estaría distribuido entre aquellos que no tienen ningún nivel de estudios, representado por el $58 \%$, y el resto de ellos con el $29,8 \%$ que hacen un total de $87,8 \%$. De ahí que la prevalencia de trabajos precarios que se desarrollan mediante actividades extraprediales sea poco remunerado y sin prestaciones, para respaldar los niveles de vida similares a satisfacer de manera adecuada las necesidades de la población. Lo cual explica el hecho de que encontramos una gran diversidad de actividades o trabajos realizados por pequeños productores o campesinos, entre las que se encuentran:

- $4 \%$ se desempeña como jornalero

- $2,5 \%$ trabaja como albañiles o peones de albañil

- $2,3 \%$ son obreros

- $6,7 \%$ se dedican a la parcela

- 30,2\% se dedican a otra actividad en la que sobresale hacer mandados, cuidar personas de edades infantiles o ancianas, fayuquero, llevar a las borregas a pastar, entre otras.

- El 3,4\% está desempleado y el restante 50,9\% es ama de casa o se dedica a realizar actividades domésticas.

\section{Discusión}

En Zacatecas, alrededor del 86 \% de los productores tiene predios menores a cinco hectáreas. Poco más del $10 \%$ mantiene condiciones favorables que le permiten incursionar en el mercado interno y externo, o engrosar las filas de los campesinos que

3 Por ejemplo, con preparatoria terminada, profesionales, o aquellos que cuentan con otros estudios. 
están inmersos en un proceso de proletarización y desaparición. De esta forma se aumentan las filas del proletariado pauperizado, muchas veces excluido de los procesos productivos formales de sus lugares de origen. El resto, alrededor del $4 \%$, está en condiciones de competir con el mercado externo (De Luna, 2010).

El incremento de productores campesinos y comuneros, señalado de manera oficial (INEGI), hasta alcanzar poco más de 255.000 predios menores o iguales a las cinco hectáreas en Zacatecas, pone de manifiesto algunas consideraciones. Por un lado, deja al descubierto que la mayoría de ejidatarios o comuneros tiene en posesión más de uno y hasta tres predios menores a cinco hectáreas, en terrenos separados; por el otro, muestra el nivel de pulverización que se ha gestado en la tenencia de la tierra, producto de la repartición familiar después de la muerte del posesionario inicial en la apertura de tierra ejidal y comunal. Esta situación se presenta de manera más activa en la actualidad, en la medida en que una gran parte de los poseedores tiene una edad promedio superior a los cincuenta.

Para ejemplificar lo anterior, una encuesta aplicada a una muestra aleatoria de 900 campesinos de localidades seleccionadas en el estado de Zacatecas, mostró que el 94,44 \% de ellos tenía entre 30, 50 y más años (50 \% de 30 a 49 años y 44,44 \% 50 o más años), (de Luna, 2018). En segundo lugar, la generación que se asume como nueva poseedora mediante la herencia, antes de asumir la titularidad ya estaba inserta en el mercado laboral de manera formal y en condiciones de precariedad; de manera informal, como sobre población relativa y absoluta (Acosta, 2005 y Figueroa, 2005). Esta nueva representación implicó compartir las actividades de manera itinerante con los ciclos de la actividad agrícola en el predio y aquellas que, al no demandar actividades en el mismo o demandadas de manera escasa, permitían la inserción en otras actividades formales e informales, por las que se recibía una remuneración monetaria precaria, pero permitía seguir manteniendo el vínculo con la tierra (Herrera, 2013). Finalmente se puede inferir que el pequeño productor campesino zacatecano no está exento de la vorágine generada por la acumulación de capital, aunque asuma formas diferentes en condiciones de entorno inmediato como las que lo relacionan en ámbitos externos de competencia nacional e internacional. Se debe hacer énfasis en señalar que este campesino se construye y reconstruye a partir de las relaciones productivas y de intercambio, que históricamente y su contexto inmediato mantiene con la acumulación.

Los procesos de globalización a los que ha estado expuesto el sector de la economía campesina en las últimas cuatro décadas, se derivan de las formas que adquiere la estrategia del capital para buscar la maximización de los beneficios; proceso que ha puesto en entredicho la viabilidad de la pequeña producción, al mostrar signos 
de precariedad y exclusión de los procesos productivos formales. En la actualidad, la presentación de la trayectoria de los productores campesinos zacatecanos, en términos generales, emana de tres fases de relativa importancia y especificidad, producto de la influencia del contexto internacional impulsado por la lógica de la acumulación.

La modificación del patrón de acumulación, surgida a inicios de la década de los 80, marca el primer hito bajo el cual los campesinos quedaron expuestos a condiciones que trastocan el cimiento de su lógica de reproducción. Las brechas tecnológicas entre productores de cualquier condición obstruían, tajantemente, su participación en los diferentes mercados y ponían en entredicho su reproducción. La crisis de la deuda, en 1982, dio impulso para que en el siguiente año se iniciara el proceso de transición hacia un nuevo esquema de desarrollo caracterizado por una menor intervención del Estado en las actividades productivas, la apertura comercial externa, la desregulación de la economía y el equilibrio en las cuentas públicas en el contexto de la globalización" (CEPAL, 1999, p. 9). Esta situación configuró un contexto sociopolítico y económico, derivado del proceso de integración económica mundial y las reformas estructurales operadas en la economía mexicana encaminadas a reducir la intervención estatal en el desarrollo económico, como principio de una nueva cuestión agraria, motor de la subalteridad y cimiento de la relación de confrontación (Tapella, 2004; Orozco y López, 2007; Monçano, 2014; Hocsman, 2014).

El resultado de la nueva configuración agraria, en primer lugar, ha propició un modelo polarizante que excluye las unidades de producción grandes o pequeñas, que no pueden competir en el mercado y que fomentan la concentración de la producción (C de Grammont, 2010); además, la retirada del Estado desarrollista y la incursión del mercado como nuevo garante de la distribución de los beneficios, produjo el nuevo terreno en el que se desenvuelve la economía campesina con claros signos negativos de reproducción (Kay, 2016; Noriero y Massieu, 2018; Ramisch, et al.). Un segundo aspecto, que influyó en las condiciones de precariedad y exclusión de los campesinos, tiene que ver con la modificación del artículo 27 Constitucional en 1991, la firma del TLC y la crisis del campo con la profundización de la dualidad económica (CEPAL, 1999; C de Grammon, 2010; Arteaga, 2018).

En cuanto a la modificación del Artículo 27, se puede inferir el objetivo que propone el patrón de acumulación al incentivar el término de las aspiraciones a obtener una porción de tierra vía dotación, mediante el impulso al fortalecimiento del PROCEDE para dar certidumbre individual como posesionario y con ello no solo la posibilidad de fomentar la compraventa y una mayor concentración de la misma, también en la disminución de la presión de alteridad manifiesta en los productores minifundistas campesinos. La firma del TLCAN es la consolidación de este proceso, por la gran 
velocidad de la liberación al marcar una profundización negativa en las condiciones de vida de estos productores campesinos, al excluirlos del proceso y enfrentar una disminución de los salarios reales y un lento crecimiento del empleo, haciendo difícil la situación de las familias mexicanas en general y de las campesinas en particular.

De igual forma, la dualidad productiva preexistente es complementaria e inherente al desarrollo de una economía capitalista subdesarrollada, incapaz de ofertar los empleos necesarios y remunerados de manera satisfactoria para una vida decorosa (CEPAL, 1999; De Grammont, 2010). Finalmente, la precariedad permanente en la población campesina se agudiza a partir de la crisis inmobiliaria que irrumpe en 2008. El antecedente de esta crisis muestra el declive de la hegemonía de EU ante potencias que, poco a poco, han tomado un lugar competitivo como China y la India, aunado al fenómeno de financiarización de la agricultura ${ }^{4}$ para formar la triada crisis energética, financiera y alimentaria, en la cual se manifiesta la ruptura de los mecanismos de control económico y militar de la gran potencia del norte (Rubio, 2008).

Ante esta situación de crisis agroalimentaria, generada en las postrimerías de 2008, se observa que aquellos países que han fortalecido las agriculturas nativas con base en la pequeña producción familiar y en la búsqueda de la soberanía alimentaria, son los mismos que serían beneficiados y reposicionados en esa fase de transición (dentro de los cuales no está México). En cambio, los países que siguen impulsando el modelo agroexportador serán los más vulnerables en el ámbito estratégico de la alimentación (Rubio, 2011). En México este proceso se expresa en un mayor déficit primario de USD 18.076.000 en 2007 a USD 37.737.000 en 2013. Esta cifra no se ha reducido de manera importante hasta 2017, al mantener la cantidad de USD 28.318.000 como déficit en ese sector (Banco de México, 2018). Esta situación adversa en el sector agrícola implicó un proceso negativo de las condiciones de reproducción de la economía campesina minifundista. De esta forma, el proceso adoptado por la economía sustentada en el agronegocio como cimiento de la globalización, generó mecanismos de diferenciación importantes en la economía campesina, presentándose una mayor explotación y precarización de sus integrantes en la medida que sus actividades son regularmente a destajo, no cuentan con la protección del Estado ni mantienen beneficios sociales en trabajos de la construcción, servicios domésticos y en la informalidad (Key, 2016; Noriero y Massieu, 2018).

Bajo este proceso, el radio de maniobra de la economía campesina se establece tomando en cuenta, además del contexto específico, toda una multiplicidad de estrategias de carácter económicosocial y cultural, sintetizadas en condiciones pluriactivas

\footnotetext{
4 Bajo este modelo, los precios se establecen en función de las inversiones especulativas en las commodities alimentarias.
} 
de las actividades desarrolladas dentro de la unidad de producción campesina. Las vertientes de sostenimiento y reproducción de esta unidad socioeconómica muestran aspectos relevantes en varias aristas. Por un lado, ante la imposibilidad de adquirir lo necesario para su reproducción, implicó generar estrategias que descansan en la migración temporal y definitiva de, por lo menos, un miembro de la familia campesina, pues estas dependen cada vez menos de la agricultura. En segundo lugar, el aspecto de los subsidios públicos, como parte del accionar del Estado y política pública, es vital para respaldar los aspectos de reproducción campesina, cuya importancia central descansa en las mujeres (Arias, 2013).

Este fenómeno también se observa en otras latitudes de América, como Argentina, donde la persistencia campesina se presenta apuntalada por acciones de carácter público. Allí, en la medida en que las fuerzas de la acumulación del capital inciden en los cambios productivos y laborales de los campesinos, estos se valen de los subsidios públicos para enfrentar su desaparición y permanecer, aunque sea en condiciones de exclusión y precariedad (Bendini y Steimbreger, 2013). Sin embargo, el proceso desplegado por el Estado para financiar la reproducción del campesinado, al igual que de otros grupos poblacionales excluidos del sistema, se realiza mediante la implementación de políticas públicas de corte asistencial, en tanto que el modelo de acumulación adoptado "abandona el principio de bienestar al permitir leyes laborales que reproducen la pobreza y posteriormente, tratan de mitigarla con transferencias de recursos hacia poblaciones fuertemente excluidas y en desigualdad de condiciones de carácter precario mediante la política pública" (Valdez, 2015).

Además de estos aspectos relacionados con los subsidios públicos y la migración como alternativas de reproducción y sobrevivencia, los campesinos realizan una serie de actividades en función de su contexto territorial y su cultura. Estas actividades involucran la recolección de flora y fauna necesarias para conseguir los nutrientes que su condición corporal demanda, lo que puede convertirse también en una forma de trabajo que puede conllevar un proceso productivo formal o informal, por el que reciben una determinada cantidad de recursos monetarios o en especie (De Luna, 2017).

En tercer lugar, no se debe olvidar que al interior de la lógica de la economía campesina se despliega culturalmente su aversión al riesgo (Cáceres, 1994). La experiencia que tienen los campesinos en torno a los fracasos en algunas tareas realizadas para la obtención de recursos (por ejemplo, la cosecha, el engorde de ganado, la introducción en la producción de algún producto nuevo, entre otras), han servido para que la unidad campesina pueda detectar la problemática que representa tomar decisiones negativas o fortalecer la cohesión interna y ponerla al borde de la quiebra y en peligro 
de desaparición. Estos errores son la base para mantener su aversión al riesgo, y hacia toda aquella actividad que genere incertidumbre; de allí también la importancia de mantener la lógica que gira en torno al autoconsumo. Por otro lado, se sabe que los miembros de la economía campesina poseen una facilidad de adaptación asombrosa en la heterogeneidad de territorios, en donde adquiere protagonismo el sexo y la edad de los integrantes para desplegar un sin fin de actividades de sobrevivencia y por ende de resistencia a desaparecer.

Los productores del minifundio temporalero son un testimonio vivo de la viabilidad del campesino en el presente, aunque tienen retos distintos a los planteados en la cuestión agraria clásica, la pluriactividad es una realidad en la que se inserta ese tipo de campesinos como parte de las estrategias de sobrevivencia y reproducción (Noriero y Massieu, 2018). En ese sentido, algunos investigadores destacan que lo que aparece como pluriactividad no es otra cosa que la precarización laboral; "La imposibilidad de insertarse productivamente en el mercado de trabajo y la imposibilidad de vivir exclusivamente en la actividad productiva, van configurando un escenario de subsistencia y precarización con un sesgo claramente pluriactivo" (Ramisch, Ghione, Quiroga, Bilbao y Chávez, 2013, p. X).

Si retomamos los resultados de la encuesta, evidenciamos las actividades precarias en que se desenvuelve el campesino zacatecano. Además de tener que generar los productos de su dieta, y los mecanismo de reproducción biológica y económico-social, en condiciones marginales del sistema económico dominante; también deben desempeñarse como peones de albañil, jornaleros u obreros. Otras veces realizan oficios varios: hacer mandados, cuidar personas, trabajar como fayuqueros y pastores. Esto último como consecuencia de las condiciones precarias de educación; por ejemplo, el 58 \% de los encuestados no tiene ningún nivel de estudios, 29,8 \% tiene niveles de estudio de secundaria terminada y el 5,8 \% cuenta con una carrera profesional; de tal forma que solo el 12,2 \% reúne las condiciones necesarias para acceder a un empleo con mejores oportunidades. Esto hace que exista un mayor número de trabajos precarios que se desarrollan en actividades extraprediales, poco remuneradas y sin prestaciones sociales, que les permitan satisfacer de manera adecuada sus necesidades.

\section{Conclusiones}

El productor campesino minifundista posee diversas características, aunque mantiene una homogeneidad que lo distingue y convierte en perenne: su racionalidad diferente a la capitalista y su vínculo directo o indirecto con la tierra. La relación 
subordinada que mantiene con el capital se refleja en la condición establecida con el mercado en un momento histórico determinado. Por lo tanto, la relación que sostiene con los niveles de acumulación, en el modo de producción dominante, muestra desgaste y deterioro; sin embargo, persiste su vínculo con la tierra, independientemente de la visión reduccionista que intenta ubicarlo en un contexto progresivo hacia su desaparición, mediante el proceso de proletarización. En el proceso genera condiciones de refuncionamiento prediales con su producción, y extraprediales al insertarse como población excedente absoluta.

Ahora bien, la pluriactividad, entendida como proceso de resistencia, manifiesta lo frágil de su figura conceptual, de su irreductible desaparición, en la medida en que lo producido por él es prescindible. La pluriactividad no es otra cosa que la forma precaria de insertarse en un determinado proceso productivo, remunerado o no remunerado. La forma que adquieren los trabajos en los que se inserta, se distinguen por ser a tiempo parcial, a destajo, en ámbitos de la construcción y servicios domésticos, jornaleros o en el ámbito de la informalidad.

El campesino minifundista de Zacatecas, al igual que el de otras latitudes, sobrevive al embate de la globalización. La diferencia de su persistencia y precariedad depende de la estrategia utilizada en las condiciones del contexto económicosocial, junto con la especificidad territorial y cultural del momento.

Las estrategias externas más utilizadas por los campesinos se relacionan con la migración y las políticas de carácter asistencial emanadas del Estado y de organismos internacionales, como proceso de retención de los descontentos sociales en lo rural. Estas políticas públicas muestran la estrategia política que encierran para mantener coptados sus movimientos, dado que el objetivo de disminuir sus condiciones de precariedad, hambre y pobreza han fracasado de manera recurrente. El ejemplo está presente en el programa PESA que, mediante la escuela para mujeres y la participación de los jóvenes, ha intentado disminuir esos flagelos desde hace más de 15 años en Zacatecas con magros resultados. El mayor resultado de este programa descansa en el capital político que desempeña en los beneficiarios en tiempos electorales.

A pesar de lo anterior, en Zacatecas los trabajos de mayor relevancia para la población campesina, además de la actividad de la parcela, siguen siendo: actividades de jornalero, albañil, peón de albañil u obrero; otras como hacer mandados, cuidar a menores de edad o ancianos; desempeñarse como fayuquero, pastor, o realizar actividades domésticas. A pesar de su precariedad, los campesinos minifundistas existen y persisten como algo perene anclado al modo de producción capitalista dominante. 


\section{Referencias}

Acosta, I. (2005). De campesinos a multifuncionales. La explotación agrícola familiar en México. Rev. Vínculo Jurídico, 61, pp. 38-48.

Alva, C.; Lins, G. y Gordon, M. (2015). La globalización desde abajo. Fondo de Cultura Económica, Colegio de México. https://n9.cl/in2rj

Arias, P. (2013). Migración, economía campesina y ciclo de desarrollo doméstico. Discusiones y estudios recientes. Estudios demográficos y urbanos, 28(1), 93-121.

Arteaga, E. (2019). Los movimientos campesinos en el marco del TLCAN: El antes y el después (1991-1996). López, H.; Cruz, M. y Narváez, L. (Comps.). Mujeres y Hombres rurales campesinos: entre lo sobrante y lo activo. Colofon.

Akram-Lodhi, H.; Cristóbal, K.; Borras J. y Saturnino M. (2009). The political Economy of Land and the Agrarian Question in an Era of Neoliberal Globalization. En Akram-Lodhi, H. y Cristóbal, K. (Edits.). Peasants and Globalization. Political Economy, Rural Transformation and the Agrarian Question (pp. 214-238). Routledge iss Studies in Rural Livelihoods.

Arroyo, R. (2001). Los excluidos sociales. Estudios Agrarios. Revista de la Procuraduría Agraria. 7(17), $X X-X X$.

Banco de México. (24 de agosto de 2018). La balanza de pagos en el segundo trimestre de 2018. Banco de México.

Bartra, A. (2006). El capital en su laberinto. De la renta de la tierra a la renta de la vida. Itaca. Universidad Autónoma de la Ciudad de México.

Bartra, A. (1982). La explotación del trabajo campesino por el capital. Macehual.

Bendini, M. y Steimbreger, N. (2013). Territorialidad campesina en el sur de Argentina. Cambios productivos y laborales como formas de resistencia. Utopía, 4, pp. 25-44.

C de Grammont, H. (2010). La evolución de la producción agropecuaria en el campo mexicano: concentración productiva, pobreza y pluriactividad. Andamios, 7(13), 85-117.

Cáceres, D. (1994). Estrategias campesinas y riesgo. Desarrollo agroforestal y comunidad campesina, 3, pp. 3-13. 
Cámara de Diputados. (2018). Guía de programas institucionales de apoyo a la mujer rural 2018. Gómez, M. y Reyes, M. (Comps). Altas y Bajas, Servicios Editoriales, Sociedad Cooperativa de R.L. de C.V.

Ceceñas, O. y Morales, N. (2015). Perspectivas de desarrollo de los productores de frijol en Sombrerete, Zacatecas. Rev. Ra Ximhai, 11(5), 97-109.

Comisión Económica para América Latina y el Caribe (CEPAL). (1999). Efectos sociales de la globalización sobre la economía campesina. Reflexiones a partir de la experiencia en México, Honduras y Nicaragua. https://n9.cl/8slng

Cruz, M. (octubre-diciembre de 2017). Apuntes sobre el campesinado multifuncional de Zacatecas, México. Rev. Contribuciones a las ciencias sociales. https://n9.cl/erhkq

De Luna, H. (2010). Caracterización de los productores zacatecanos bajo el neoliberalismo. Taberna Libraría Editores.

De Luna, H. et al. (2014). La unidad socioeconómica campesina no rentable pero sustentable. Congreso de ciencias sociales de la Unidad Académica de Ciencias sociales de la UAZ, México.

De Luna, H. (2017). De la lumbre al fogón: la campesina de Zacatecas en el neoliberalismo. Fontamara.

De Luna, H. (2018). Migración y mujer campesina. Hernández, J (Coord.). Entrar en las agendas de política: investigaciones sobre migración, planeación del desarrollo, voluntariado, resistencia y género. Plaza y Valdez.

Espinosa, A.; Cervantes, F. y Espinosa, A. (2009). Balance y perspectivas del campo mexicano: a más de una década del TLCAN y del movimiento Zapatista. Tomo II Globalización y respuestas locales de la agroindustria. Asociación Mexicana de Estudios Rurales (AMER).

Figueroa, V. (2005). América Latina: descomposición y persistencia de lo campesino. Rev. Problemas del Desarrollo, 36(142), 27-50.

Gimante, S.; Muñoz, M. y Acevedo, A. (2018). Evaluación de la calidad de la evidencia de los resultados e impactos del programa Estratégico de Seguridad Alimentaria (PESA) en México. Acta Universitaria, 28(4), 87-97.

Gobierno de Zacatecas. (24 de junio de 2018). Plantea Godezac que proyecto estratégico de seguridad alimentaria tenga proveedores locales. Estado de Zacatecas. https://www.zacatecas. gob.mx/plantea-godezac 
Herrera, F. (2013). Migración: vulnerabilidad, precariedad. Iztapalapa. Revista de ciencias sociales y humanidades, 75, pp. 5-14.

Hocsman, L. (2014). Horizonte para la producción campesina y agricultura familiar en el modelo agroalimentario hegemónico mundial. Visión desde el cono sur. Agriculturas campesinas en Latinoamérica: propuestas y desafíos. Editorial IAEN.

Instituto Nacional de Estadística y Geografía -INEGI. (2010). Censo General de Población y Vivienda 2010. https://n9.cl/ubypf

INEGI. (2013). Anuario Estadístico Agropecuario (2013). INEGI.

INEGI. (2007). Censo Ejidal 2007. https://www.inegi.org.mx/programas/cae/2007/

INEGI. (2016). Estadística de la Industria minerometalúrgica. INEGI.

INEGI. (2017). Anuario estadístico y geográfico de Zacatecas 2017. https://n9.cl/2iuuv0 .

INFOSIAP-SAPARPA (2017). "Información Agroalimentaria y Pesquera”. Disponible en http://infosiap.siap.gob.mx/anpecuario_siapx_gobmx/apecmpio.jsp?id=4

Kay, C. (2001). Latin american Peasantries. Briceson, C.; Kay, C. y Mooij, J. (Comps.). Disappearing peasantries? Rural labour in Africa, Asia and Latin America. ITDG Publishing.

Kay, C. (2016). La transformación neoliberal del mundo rural: procesos de concentración de la tierra y del capital y la intensificación de la precariedad del trabajo. Revista Latinoamericana de estudios rurales, 1(1), 1-26.

Llambí, L. (1991). Procesos de transformación del campesinado latinoamericano. El campesino contemporáneo. Cambios recientes en los países andinos. Tercer Mundo Editores.

Marx, K. (1982). El proceso de producción del capital. El capital, Tomo I. Siglo XXI.

Marx, K. (2009). El proceso global de producción capitalista. El capital, Tomo III. Siglo XXI.

Monçano, B. (2014). Cuando la agricultura familiar es campesina. Agriculturas campesinas en Latinoamérica: propuestas y desafíos. Editorial IAEN.

Meillasoux, C. (1987). Mujeres, graneros y capitales. Siglo XXI. 
Mueller, M. (14 de septiembre de 2009). El abandono de los acuerdos de Bretton Woods en 1971. Oro y finanzas. https://www.oroyfinanzas.com

Muñoz, E. (2014). Estudio de la implementación de política pública desde la perspectiva organizacional. El caso del Proyecto estratégico de Seguridad Alimentaria en el Estado de Zacatecas, 2005-2013. [Tesis de maestría]. El Colegio de San Luis. San Luis Potosí, México.

Noriero, L. y Massieu, Y. (2018). Campesinos maiceros en Tlaxcala: viabilidad, caracterización y respuestas ante el maíz transgénico. Rev. Sociedad y ambiente, 6(16), 179-206.

Orozco, M. y López, D. (2007). Estrategia de supervivencia familiar en una comunidad campesina del Estado de México. Ciencia Ergo Sum, 14(3), 246-254. http://www.redalyc.org/articulo. oa?id=10414302

Ramisch, G.; Ghione, P.; Quiroga, M.; Bilbao, L. y Chávez, F. (2013). Un acercamiento al papel de las políticas sociales en la persistencia de pequeños productores pobres, el caso de Ancasti, Catamarca. La agricultura familiar en Argentina. Diferentes abordajes para su estudio. Ediciones INTA.

Rubio, B. (2009). De la crisis hegemónica y financiera a la crisis alimentaria. Impacto sobre el campo mexicano. Revista Argumentos. Nueva Época. 21(57).

Rubio, B. (2011). La nueva fase de la crisis alimentaria mundial. Revista Mundo Siglo XXI, 24(VI), 21-32.

Sader, (2015). Informe de la Secretaría de Agricultura y Desarrollo Rural: Segundo Informe Trimestral de Resultados 2015, Proagro Productivo. Editorial: Secretaría de Agricultura y Desarrollo Rura. México. https://www.gob.mx/agricultura/documentos/segundo-informe -trimestral-de-resultados-2015-proagro-productivo

Teubal, M. (1993). Agroindustrial modernization and globalization: Towards the new world food regime. Working Paper Series Núm. 162, Institute of Social Studies.

Torres, F.; Herrera, F.; Vizcarra, I. y Lutz, B. (2015). Etnografía institucional del proyecto estratégico de seguridad alimentaria (PESA) en una comunidad mazahua. Rev. Nueva Antropología, 28(82), 51-81.

Tapella, E. (2004). Reformas estructurales en Argentina y su impacto sobre la pequeña agricultura. ¿Nuevas ruralidades, nuevas políticas? Rev. De Estudios sociológicos, XXII, p. 66.

Valdés, X. (2015). Feminización del empleo y trabajo precario en las agriculturas latinoamericanas globalizadas. Cuadernos de antropología social. 41, pp. 39-54. 